$\begin{array}{ll}\text { DE } & \begin{array}{l}\text { DE GRUYTER } \\ \text { OPEN }\end{array} \\ 10.1515 / \text { cris-2016-0003 }\end{array}$

\title{
FAIRNESS, TRUST, AND THE REMOVAL OF DISSATISFACTION
}

DAVE GANNON 


\section{INTRODUCTION}

"The thing that makes us love our jobs is not the work that we're doing, it's the way we feel when we go there. We feel safe, protected; we feel that someone wants us to achieve more and is giving us the opportunity to prove to them and to ourselves that we can do that" (Simon Sinek, cited in Chapman, 2015).

Yet, despite the optimistic viewpoint expressed above about what our working experience should be, many people find a very different experience. According to the CIPD (2015a, p. 5), when questioning employees about their desire to change their workplace, one fifth indicated that they were looking for alternative employment, with fifty-four percent of those indicating it was to look for increased job satisfaction. This is a situation which is rather odd, as if we recognise that as above it is often the experience of work rather than the work itself which gives job satisfaction; it seems that organisations are perhaps making mistakes or errors in their handling of employees and creation of company culture. Another CIPD report, this one looking into workplace conflict (CIPD, 2015c, p. 19), adds that "what is at stake is not only the technical aspects of employment contracts, but the wider psychological contract that underpins the employment relationship" when examining the causes for workplace conflict. If employees feel that the 'psychological contract' is broken, then de-motivation is often the main outcome, which can of course lead to lower productivity and even to the loss of the employee.

Surprisingly, despite a great deal of literature devoted to this subject, organisations continue to make mistakes in their approach to employees. Perhaps one of the most appropriate for discussion of this situation is Frederick Herzberg's Two Factor Theory, especially his discussion of hygiene factors, which can lead to dissatisfaction if ill-considered or ignored, resulting in the removal of the opportunity for motivation to happen, no matter the practice or offer by the organisation. This article will examine this issue and then add in a further factor which is not always overtly discussed, not just the actual dissatisfaction which may exist in the workplace, but also the 'perceived' dissatisfaction which exists, whether it is based on a reality or not. This article will argue that if both causes for dissatisfaction are addressed, both real and perceived, then the organisation has a better chance of engaging its employees, removing dissatisfaction, and being in a place to motivate them and providing them with something which resembles the experience as described by Sinek above.

\section{HERZBERG'S TWO FACTOR THEORY}

Frederick Herzberg, in his article on motivation in the Harvard Business Review (1968) attempted to make it clear that for organisations and managers to engage and motivate their staff, they first had to understand that "the factors involved in producing job satisfaction (and motivation) are separate and distinct from the factors that lead to job dissatisfaction", and that unless the basic conditions exist in the workplace that result in no job dissatisfaction, the conditions for motivation will not exist where job satisfaction is the result. He made clear that job dissatisfaction and job satisfaction are not opposites, but two different concepts. As he remarked (HBR, 2003, p. 5),"the opposite of job satisfaction is not job dissatisfaction but, rather, no job satisfaction; and similarly, the opposite of job dissatisfaction is not job satisfaction, but no job dissatisfaction."

In essence, if factors in the workplace/experience of employees create job dissatisfaction, the possibility of later creating job satisfaction is not possible. Herzberg's investigation (and others) (HBR, p. 6) identified the following as hygiene factors which affected job attitudes (dissatisfaction or no dissatisfaction) directly; company policy and administration; supervision; relationship with supervisor; work conditions; salary; relationship with peers; personal life; relationship with subordinates; status; and security. The four most promi- 
nent, playing the greatest role in producing job dissatisfaction were (HBR, p. 6) company policy, supervisors, relationship with supervisor, and salary. This is something which can be seen in CIPD (2015c) reports on employee experience and workplace conflict which identify similar factors which lead to dissatisfaction.

Therefore, in order to move to a place where a discussion of job satisfaction (motivation) can begin, these hygiene factors need to be addressed first of all.

\section{REMOVAL OF DISSATISFACTION}

According to Halogen and the CIPD (2015) employee outlook report, fifty-five percent of employees stated that they would prefer to work in an "organisation with a family feel, held together by loyalty and tradition". The report further states that one third of all employees feel that the most important behaviour line managers should display is 'fairness' in how they treat them, the second most important is to be 'open and honest'. What this indicates is that the idea of being treated fairly is one that needs attention, particularly if unfair treatment is provided - line managers taking credit for the work of others, unfair distribution, etc. - and even if this is perceived rather than reality. In essence, it seems as a breach of trust by employees, leading to dissatisfaction.

There is perhaps room to think more about specific components which Herzberg identifies and examine how they might work in practice, where awareness might lead to greater understanding and thought concerning creating conditions and management behaviour in the workplace. One area in particular worth examination is that of 'trust', as defined as (Oxford Dictionaries) a "firm belief in the reliability, truth, or ability of someone or something", and its role in creating dissatisfaction where trust is broken, by either the organistaion or its representatives, thereby preventing the potential for motivation.

Herzberg's argument is quite clear: the existence of dissatisfaction in the workplace precludes the possibility for motivation to occur. It does not mean that motivation will occur if dissatisfiers are removed, simply that the conditions will be present where motivation could occur. In a sense it is possible to model it to:
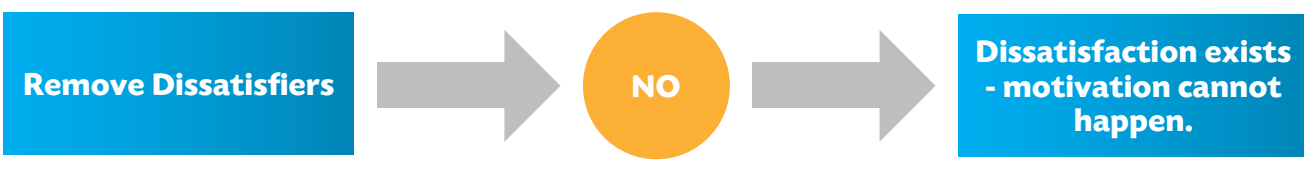

Or, as:
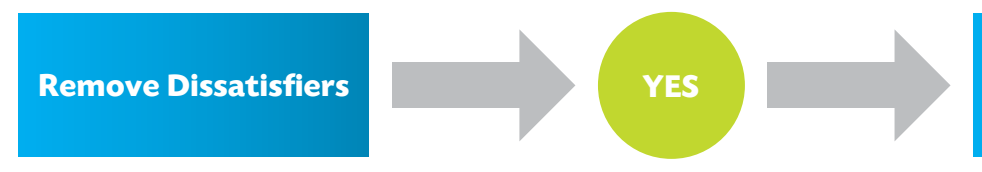
No dissatisfaction
exists - motivation can happen.

By removing elements leading to dissatisfaction such as a lack of fair treatment in terms of compensation, supervision and status, working conditions and administrative practices, job security, we create the conditions where motivational practices can be applied - the conditions exist where an organization may be able to motivate its employees. What we can take away from this is that if an organisation understands that dissatisfaction exists, they can take steps to eliminate it, improving the conditions of the workplace and employee engagement thereby creating conditions for the implementation of motivation strategies. Such an implementation might be through the following: 
1. PROCEDURAL FAIRNESS - The organisation consistently applying rules and transparency to its employees, in terms of salary, evaluation, selection, promotion, etc. A major cause of workplace dissatisfaction often stems from the idea of being treated unfairly, whether this actually takes place or not. According to the BIS (2009, p. 64), thirty-four percent of respondents reported being treated unfairly compared to others at work. When questioned as to what the unfair treatment was related to, the following was reported (BIS, 2009, P. 71), twenty-five percent reported it due to being ignored, eighteen percent reported it due to the type of work being given, seventeen percent indicated it was in terms of workload whilst fourteen percent indicated that it was to do with assessment of work, performance, and appraisal. Therefore, by applying the rules equally to all and creating an internal culture whereby all employees and managers make strenuous efforts to treat others equally it will have the potential to remove dissatisfaction on the part of those employees who might feel less favourably treated or slighted.

2. DISTRIBUTIVE FAIRNESS - The organisation consistently providing fair distribution of compensation, rewards and consequences for all members of the organisation, no matter their position or role. Yet, the BIS report (2009, p. 62) states that the two largest areas for grievance when it came to employment rights were problems with pay and receiving a contract or written statement of terms and conditions for the job. It is not enough simply to have policies in place, but to actually carry them out and understand the importance of them for the employees of the organisation. Yet it should go beyond this, with a sense of transparency in the organisation so that any potential 'negative perception' does not have room to grow. One simply has to imagine the reaction of an employee to finding out that a colleague receives different remuneration for the same task to understand the importance of this issue. Firstly, that they are paid a lower amount resulting in feeling unappreciated and under-valued; secondly, that this is institutional policy, and the organisation encourages unfairness as policy.

3. INTERACTIONAL FAIRNESS - The organisation, through its managers and decision-makers interacting with employees in a manner which is seen as fair, consistent, and appropriate. Whilst a rather obvious idea, sadly, the workplace experience does not always conform to such ideas. The BIS report $(2009$, p. 77$)$ indicates that those who reported experiencing negative behaviour pointed to a range of experiences, the most common incidents were those who reported unreasonable management demands in terms of workload and deadlines, followed by personal attacks, of being treated in a disrespectful or rude way. Such behaviour, especially if it has built on a previous sense of unfairness, will of course lead to dissatisfaction and its attendant issues for the organisation. Managers and decision-makers simply have to put themselves in the employee's place to see how such behaviour might be taken. Whilst some managers may feel that or subscribe to the idea that 'if you want something done quickly, give it to someone who is busy' or that setting unrealistic expectations leads to challenges and improved performance, for many employees it will have the opposite effect and goes against the idea of respect and fairness in the workplace.

Therefore, if we follow the reasoning of creating a culture of fairness encompassing procedures, distribution and interactions, thereby removing elements leading to dissatisfaction, or as Hope-Hailey (2014) states, "the best we can hope for is that we eventually stop talking about trust and we return to a situation where trust is a taken-for-granted assumption within the workplace and beyond", we could get the following:

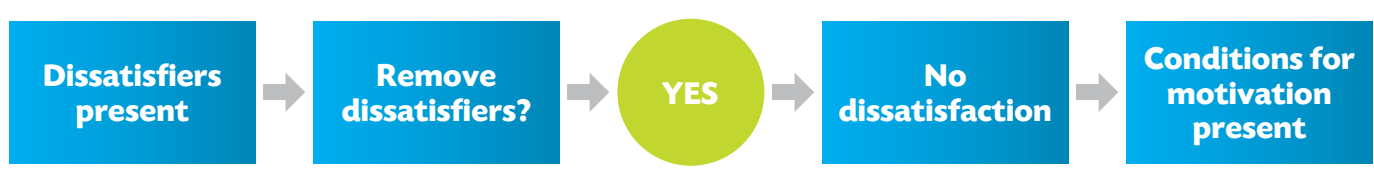

Or, if not done or suitably addressed:

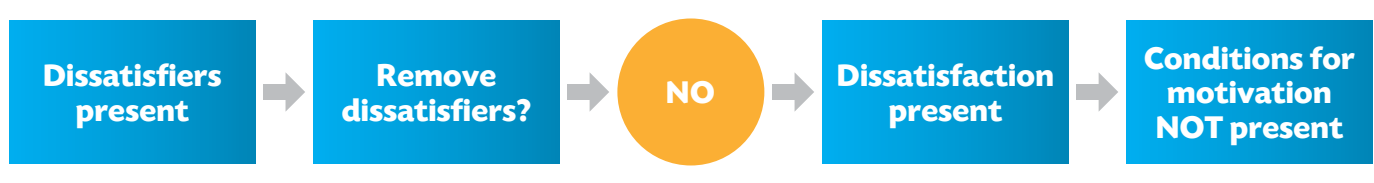


Yet, whilst it seems rather straightforward, the organisation simply identifying those elements or behaviours which lead to employee dissatisfaction, there is perhaps a failure here to consider 'perception', the way in which (Oxford Dictionaries) "something is regarded, understood or interpreted". Past treatment, such as being ignored, brushed off, disrespected, or over-looked (as mentioned in the previous discussion) will give the individual employee a sense of having been treated in an unfair manner. By being treated in their eyes 'unfairly', then, perhaps they will not feel they are treated justly, even when treatment changes. As Robinson (1996, p. 576) states it is the "employee's belief that a breach has occurred that affects his or her behaviour and attitudes, regardless of whether that belief is valid or whether an actual breach took place". The psychological contract, which an employee feels has been created between them and the organisation is vital, and if its terms are broken, it is seen as a breach of trust. If an employee has had a negative prior experience, then (Robinson, 1996, p. 577) they are more likely to "look for, find and remember incidents of breach, even in the absence of objective breach, because it is consistent with his or her low prior trust". What it might entail, something which the organization wishes to avoid if possible, is the following conditions:

When an employee perceives a contract breach by the employer, he or she perceives an inconsistency between the employer's words and actions. As a result, the employee loses confidence that the contribution made today will be reciprocated as promised, by the employer in the future and the employees motivation to contribute to the firm declines. (Katz, 1964, cited in Robinson, 1996, p. 579)

If we attempt to see this in operation in the workplace, we might find something like the following situation:

A customer service agent is required to complete 14 pieces of work per day - responding to customer queries. One day they decide to solve a case that has been accumulating for 4 years, spend the whole day on one piece of work but in the end they solve it. However, as they did not achieve their quota they were heavily criticised by their line manager and given a warning. That particular customer service agent may feel that their commitment to providing their customers service has been disrespected, and they feel that the management reaction was un-just - in essence, they may feel a sense of betrayal - a breach of trust as they went to work expecting that in return for doing their best they would be treated with respect and appreciation. Furthermore, due to the nature and application of Key Performance Indicators (KPI's) often being based on quantitative methodologies and a failure to consider that only a (CIPD, 2014, p. 4) "combination of hard and soft data that together... provide useful insights", a lack of apparent appreciation for the work completed was created. Perhaps due to the design and implementation, in this case by only using one metric, a negative reinforcement has occurred, their trust in the ability of the organisation has been broken as well.

Therefore, as they feel they have been treated unfairly, dissatisfiers are present in the workplace for them. Actions which are taken by the manager later, an apology or praise for other work, will not have the desired effect as there exists the perceived view of dissatisfaction stemming from their previous experience. People will seldom feel treated justly even when treatment changes as the perception of injustice has caused damage which may take a longer time to repair. 
In the case of our customer service agent above, perhaps they will be given a new position by the organisation, for example, responsibility for long-term issues. Will they see it a positive? In some instances, due to the previous sense of injustice, they will see the new role not as a positive but as a negative job enlargement or simply a device to keep someone working without any genuine commitment to it. As Nisbettt and Ross (1980, cited in Robinson, 1996, p. 594) argue "even when faced with evidence that should disconfirm their prior beliefs, individuals are able to devise causal explanations for that evidence that allows the prior belief to remain intact."

The aim is to avoid this:

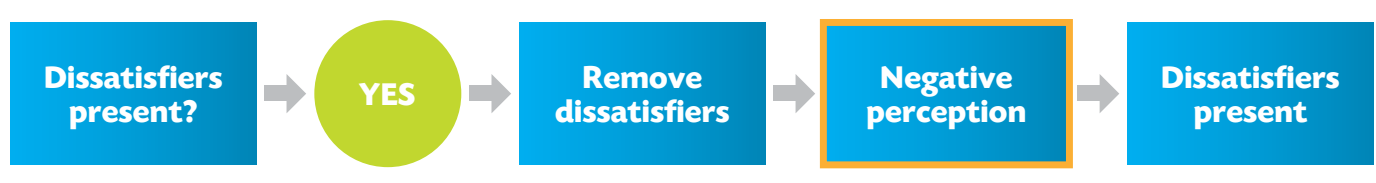

And to try and get here:

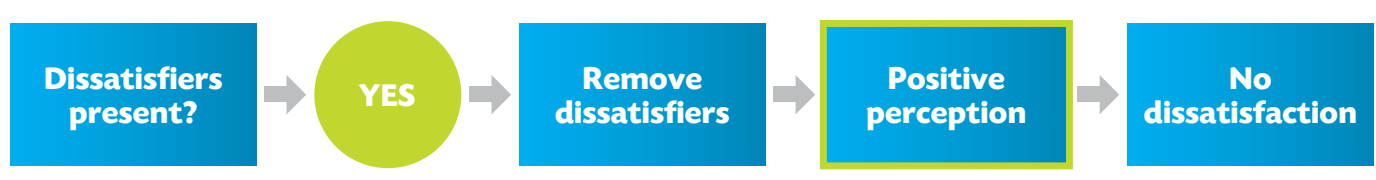

What the organisation can learn is that it is not simply a matter of removing dissatisfaction, but also if they have existed, removing 'perceived dissatisfiers'. They basically have to rebuild a positive relationship with their employee, to rebuild the sense of fairness and trust, a new challenge and not something easy to accomplish immediately or in the short-term. This challenge depends on a number of variables, the individuals involved, their connection to their organization, and not least the recognition by the organisation that action needs to be taken. If a typical example of someone who has a sense of injustice, the organisation being aware decides to take action, the following might occur.

Doing too little.

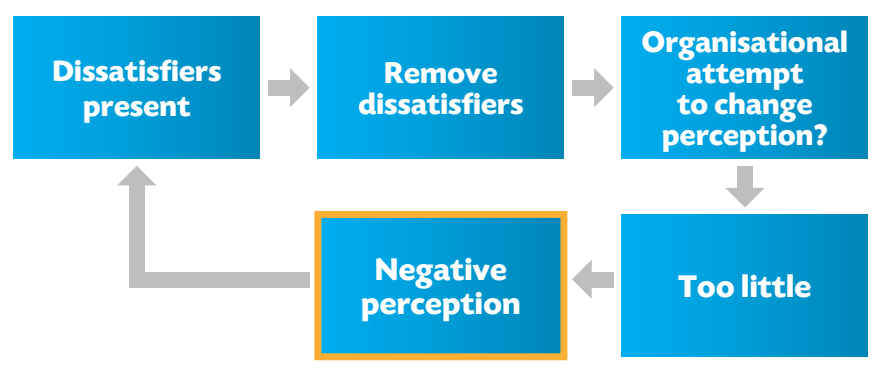

In this case, doing too little - a one-time effort, or no continued development - does not lead to change in perception - a dissatisfied employee continues to be dissatisfied. The attempt does not seem serious or seems false in the mind of the individual. 
Doing too much.

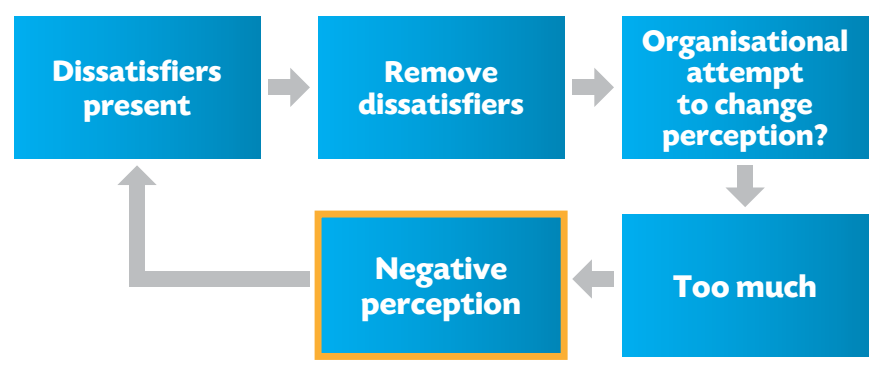

In this case, doing too much - exaggerated effort to create trust - also results in a negative perception. Negative treatment often leads to a negative interpretation, even of positive treatment, as in the case of the customer service agent above. Again, the behaviour seems false in the mind of the affected individual.

The question then is for the organisation to break the cycle and to find the correct approach to change the perception from negative to positive. Perhaps the most common mistake here is to believe that a one off reward will provide a 'fix'. For many people, trust is not restored so quickly, and it is due to repeated actions where trust will be restored incrementally as in the representation below. As the CIPD (2012, p. 37) notes, "a loss of trust can happen swiftly but its repair can take a lot of time and energy."

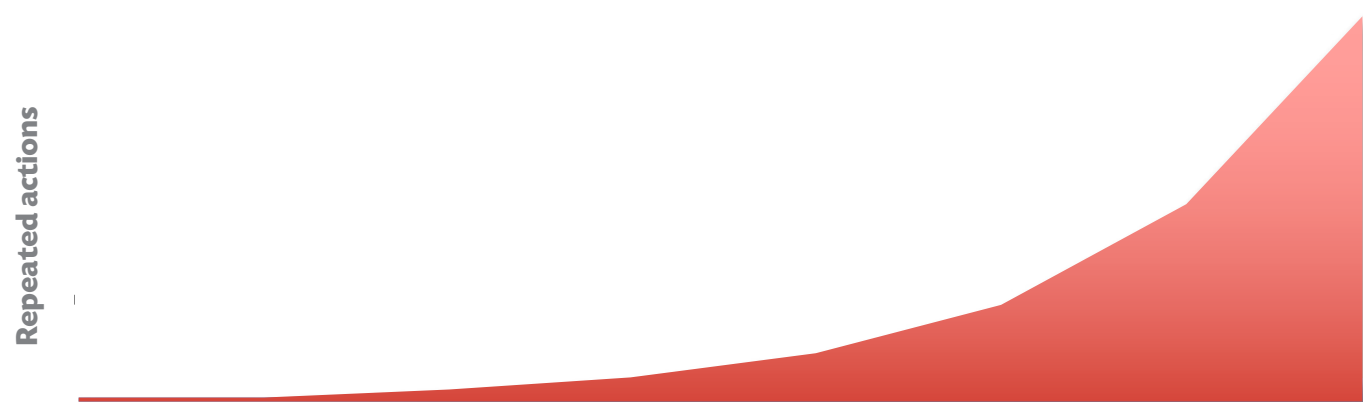

Strength of trust

With employers reporting increasing difficulty in attracting and recruiting talent, with the CIPD (2015b, p. 4) reporting that of the organisations questioned, "over three-quarters experienced recruitment difficulties last year", can organisations really afford not to pay attention to creating a workplace environment which removes dissatisfaction? There are still those organisations and managers who feel that putting such effort is rather a waste of resources. They may point to the orientation of the firm, to individual motivation of employees, to not understand how to go about such activities, etc. However, despite the objections they raise, it can still be argued that it is worth creating a positive work environment in order to remove dissatisfaction, both 'perceived' and 'real'. As David Guest (CIPD, 2016, p. 6) argues in the CIPD's collection of thought pieces "a positive employment relationship at the individual level, will be characterized by perceptions of high trust, fairness, employment security, a positive and fulfilled psychological contract and a high quality of working life." The result of such conditions can lead to (CIPD, 2016) "higher commitment, citizenship behaviour and individual performance". 
A simple answer on how to do this would be to ask employees, to examine the issues which they report on as increasing dissatisfaction at work. Studies, such as those carried out the CIPD and the UK government, reveal rather clearly what employees look for and what they would like to avoid in the workplace. As the CIPD (2015c, p. 4) notes, "we need robust cultures in which it is possible to challenge and hold each other to account, and do so without undue risk of creating damaging relationship conflict." The key points here being; holding each other to account; meeting responsibilities; and engaging in discussion without causing negative conflict, whatever the situation of the organisation or employer.

Employee Cultural Background - One argument which can be made is that some cultures see power distribution inequality as more acceptable/normal than others. What might be inferred from this, is that treatment or unequal treatment may be seen as a norm and therefore not cause dissatisfaction, or that trust is gained back faster or is actually not necessary as such behaviour is seen as a normal part of working. Furthermore, in cultures where there is a sense of commitment to the success of the organisation as a whole rather than to individual goals, a commitment to fairness and removal of dissatisfaction may not be deemed immediately necessary on the part of the organisation.

However, as such organisations tend to have a longer term focus, there is a need to attract employees for the future and an organisation which does not treat its employees well or pays little attention to their needs and the workplace environment might struggle with this. Furthermore, whilst the organisation may not experience high turnover of staff due to attitudes to work, the inputs provided by employees may be lessened, and the organisation may struggle to achieve its strategic goals. Expecting a commitment from employees but showing no commitment in return, such as laying off employees in difficult economic times will hardly engender a sense of trust or commitment to those who remain.

Employee Engagement - Another possible consideration is the reason behind choice of workplace by the individual. Despite discussions in Human Resources for searching for those employees who 'buy-in' to the organisation, with (HBR, 2013, p. 1) seventy-two percent of employers seeing the need to engage employees and have them identifying with the organisation, the simple truth is that many employees may take employment for a multitude of other reasons - gaining experience, simply receiving a salary or wage, etc. If the organisation is dealing with such an employee as in the latter case, and their employment is tied to other reasons, will such trust building activities actually work or have any impact? In fact, the concept of dissatisfaction may not actually apply in the sense that that the experience of particular employment may be a dissatisfier, as they wait for alternative employment or fulfill their goal of being there - saving money, gaining experience for a CV etc. Although, it does require an organisation to actually know the motivations for its employees to be in the workplace. With the CIPD (2015a, p. 4) reporting that thirty-six percent of employees are feeling engaged, either people are taking jobs or organisations are failing in their attempt to engage with them. Whilst fifty percent expressed satisfaction with their jobs, again, the large amount who did not indicate this again highlights an issue. The reasoning here might be that spending time and effort on those who intend to leave might be a waste.

Yet, whether this is a sensible approach is not clear. With employers reporting that they are facing in difficulties in reporting, employee retention and development would seem to be crucial to filling their needs. Therefore, by creating a culture of trust, removing dissatsifiers and negative perceptions, employees who might otherwise be lost to the organisation, may engage with the workplace and begin to see it as a place of work with potential for them, buying in to the culture and perceived values of the organisation. Even if they gained employment for other reasons, the positive experience they may have within an organisation with a positive culture may allow for a shift in attitudes, and what was once seen simply as a means to an end may now become something different, a desire to stay within the organization and to make a contribution. 
Employee Career Focus - Research and studies tend to indicate that different generations have a different attitude to careers and length of stay within an organisation. For example, "ninety-one percent of Millennials (born between 1977-1997) expect to stay in a job for less than three years, according to the Future Workplace", according to Meister (2012). Will dissatisfaction in the workplace actually impact these employees, or if it does, will any activities undertaken by the organisation have any effect? Are they even necessary, despite perhaps an issue with employer brand which a lack of activity may entail?

Yet, in today's working environment, can an organisation take such an attitude? Can it afford to let millennials go - according to a Deloitte survey in 2016, "Forty-four percent of Millennials say, if given the choice, they would like to leave their current employers in the next two years". Yet, it also reports that those who are "likely to remain longest share their organization's values, and are more satisfied with its sense of purpose and support of professional development". Putting effort in the activities generate greater loyalty and less dissatisfaction. Conversely, with older employees indicating a willingness for longer term employment, with older workers looking to, according to the DWP (2013, p. 5) "planning to work beyond the state pension age", it would again seem important that to keep them, the necessary environment should be created or re-established, attracting a more diverse workforce allowing the organisation to pursue its goals.

Employee Contract Terms - With the rise of the flexible organisation and the division between core workers and contractual fringe, the question which could be asked is whether the contractual fringe employees would have the same feelings as those employed full-time, and whether the organisation needs to concern itself with them. For example, a temporary worker hired by an agency to fill a function during a busy time - customer billing, etc. - whilst given the same responsibilities as a full time employee, is often provided less than the benefits and rewards of their full-time colleagues. Firstly, the obvious question raised is whether such the unequal treatment/nature of their employment is going to impact how they see the organisation and view the treatment they receive, especially if they are doing the same work as everyone else. Will a sense of unfairness pervade and will it impact their motivation for doing the work? Secondly, as Robinson argues, if they go into an organisation with a negative viewpoint (as perhaps created by their temporary working status) will unequal treatment impact them as someone who has chosen to work for the organisation full-time? Or does the very fact that they are temporary, mitigate against this?

To counter this, one argument that perhaps could be made is the fact that treatment as a temporary employee will impact their desire to transition to that organisation - in either a positive or negative way. Perceiving others (full-time employees) gaining more, better conditions and perks may motivate them to want the same - especially if they have been working for the organisation for some time and have developed a stake/attachment to the organisation/work. In this case then, the argument goes that unequal treatment would be in a sense beneficial. Yet, to what extent would this actually work? Surely someone who has received unequal treatment is more likely to go elsewhere where conditions may be better. Due to unequal terms and conditions, which do not happen just from poor management practice, but from an organisational level, might develop a sense that conditions of employment are unfair and there is no wish to work for the organisation. A 1999 study by Industrial Relations Services cited by Eurofound, reported that half of the companies surveyed for the research perceived temporary staff as being less reliable, less committed and less well trained than permanent employees. A quarter reported that costs had increased as a result of using temporary employees. A loss, especially as this individual will probably have been invested in terms of training and service delivery. Is it wise to let them go and start again with someone new? 
A further point to consider is whether a temporary employee who feels they are have been treated unfairly in some respect will actually care or be interested in any remedial actions the organisation takes to try and repair the damage, as they often have the ability to release themselves from their work obligations fairly easily. To make the same point as above, contractual workers require training and investment and to keep repeating the same exercise with new employees would seem to be a wasted investment. With organisations tending to trim training budgets in difficult economic times, is this a wise course of action to take?

A further consideration to make is the need for all employees to provide quality work and consistency. Whether they are core employees or contractual fringe, their work plays a vital role for the organisation, whether interacting with internal or external customers, and a loss of quality will impact the operations, reputation, etc. Therefore, with the need to provide consistency and quality from all employees (no matter their status) the environment, conditions and atmosphere should be the same in order to gain identification with the work/organisation and fulfill the function for which they were hired effectively.

Employer Commitment - Beyond the individual employee and their feeling/motivation for work, the organisation needs to be examined. Whilst we may assume that any business is looking for long-term sustainability, the truth is that many organisations exist simply for the short-term to meet a specific goal, and therefore for these organisations such an interest in employee well-being and ensuring dissatisfiers are absent from the workplace and may not actually be a concern as they are simply looking for a short-term commitment from their employees, and therefore greater effort or consideration is unnecessary. The offering of high rewards for such work may be seen as a way to mitigate the need for any commitment. There is another question which needs to be asked, whether the organisation sees value in the engagement of its employees or not? Whilst an older example would suggest that in certain industries such as manufacturing, employee engagement is less of a requirement or of less necessity, such attention to employee well-being and the health of the organisation may not be part of their strategy or even consideration. If the situation occurs where employees are seen as disposable, easily replaceable, then it might not be in the interests of such a business to invest in the necessary changes to the working environment, removal of dissatisfaction through the creation of trust.

Yet, such an organisation may struggle to leverage more than the minimum effort from its employees. If productivity and quality are important, someone who has experienced dissatisfaction is less likely to make more than a basic input. If there is recognition that employees 'are' the organisation, that innovation and development stems from people, not technology, then an organisation which fails to consider the implications of dissatisfaction in the workplace is unlikely to maximise the contribution its employees can make. However, even if this is true, in order to maximise the abilities and contribution of employees, even in a short time frame, certain conditions need to be met. Promises have to be kept and basic conditions have to be present in order to leverage the skills of employees. It would seem that even here, an organisational culture committed to providing fairness, removing dissatisfaction would lead to better results than those without, surely the point for any organisation with this kind of vision.

Employer Brand and Initial Sense of Trust and Expectation - There is a great deal of discussion on the concept of Employer Brand and its importance, especially for sourcing talent, attracting those candidates who will 'buy-in' to the values or the organisation, etc., if an employee has an initial sense of trust then they are more likely to ignore potential breaches of trust, as Robinson (1996, p. 594) notes, "employees with low initial trust in their employer experience a greater decline in their trust following a perceived breach than did employees with high initial trust in their employer." The issue though is the attitude of the employer towards its creation, numerous businesses whilst professing its importance indulge in activities which often damage it, and the extent to which it is a factor in employees using it is as a factor in choosing employer. 
Research would indicate that it does, as the CIPD (2015b, p. 5) explains, "organisational values and good working practices are the elements of employer brand most commonly seen to be important for attracting candidates", if so, then it may prevent "perception of dissatisfaction" in the workplace. Although it might also be argued that an organisation with a good employer brand is probably going to be better at managing employee expectations in the first place. What it indicates is that if an organisation pays attention to its culture, its working practices, its brand as an employer will improve and will improve in terms of attracting talent and retaining those skills of its existing employees. One further consideration is that organisations are making a mistake in believing that by offering 'physical gimmicks' they are seen as an attractive employer to work for. Whilst nice surroundings may be pleasant to work in, studies have repeatedly shown what was first understood by the Hawthorne studies of the 1930s was that change of physical surroundings does not improve productivity and attitude, organisations which pay an interest in people do.

Management Ability - One argument that could be made is an organisations inability to find managers who have the requisite skills and attitudes for such a change or simply believing that existing management abilities are suitable when they are plainly not. The CIPD (2015c, p. 11) reported that the largest number of issues and conflict that employees had was with their line managers and superiors, an indication that perhaps this is not quite true. However, having policies in place, organisational awareness of dissatisfaction amongst employees is one thing, the normal day-to-day work of implementing such policies of regaining trust often fall on line managers, the question then being raised is whether they as individuals possess the ability and skills to implemented them in a genuine way. After all, they are just as human as everyone else, subject to their motivations for being in that particular employment with their own views on individuals which work as part of their team. With the wrong management, such policies will often be impossible to implement successfully and trust will not be regained.

Assumptions of managers towards their team and employees will often impede or blunt their ability to regain trust. It does require an organisation having a set of managers with the underlying assumptions in order to implement policies to regain or create trust, never more so than when the organisation faces difficult times. Whilst discussions around assumptions tend to be contentious, the fact is an organisation needs management who believe in what they are doing as any pretense will often be uncovered as managers fall back on older practices/ideas when faced with challenges, undermining the efforts to win back the trust of employees and remove dissatisfaction. As Schein (2011, p. 161) has argued, "there is no point in suggesting content to people because if it does not fit their assumption sets they would not do it anyway or they will do it in an incongruent way and will fail."

Such people with the appropriate assumptions do exist; it is however the challenge for the organisation to amend its practices in searching for such people who have the abilities, to rethink recruitment practices, that assumptions are important not experience and the CV. If an organisation can recognise this, then such arguments will be less likely to be made. As Fernandez-Araos (HBR, p. 49) argues, "I am convinced that organizations and their leaders must transition to what I think of a new era of talent spotting - one in which our evaluation of one another are based not on brawn, brains and experience, our competencies but on potential." Only those people who have the appropriate underlying assumptions will be able to implement any change within the organisational culture, behave in such a manner as to establish or re-establish trust with employees through their actions. It is up to the organisation to decide on its behaviour and select those who have the ability to implement it accordingly.

Influence of Informal Team Leaders - In any organisation or team, there are the official leaders in terms of appointed supervisors, team-leaders, line managers, etc., but an informal leadership also exists within the employees themselves, those that others recognise as the essential glue holding the team together, those others look to. Without these employees being on board and trusting the organisation then efforts to remove dissatisfiers for others will often fail. It does raise the argument over whether an organi- 
sation should be targeting its efforts or not, but if dissatisfaction is present already, perhaps it is realistic to believe that not everyone is going to respond, and that greater impact can be had by directing efforts to 'on-boarding' those who others will pay attention to. It could be argued that not everyone will be salvageable, therefore is it prudent to input effort into those where a return is impossible?

The answer here again is 'yes'. If a system of targeting is utilised, the unintended consequence is that the efforts will often fail on those the organisation is trying to 'save' as they will be able to observe the continuance of unequal treatment and effort. In a sense it can be equated to survivor guilt, having to work with those who receive less will not lead to a better experience, rather a continuation of dissatisfaction. Whilst some organisations might create a policy of a uniform culture and on-boarding and engagement with some, still there is a disparity of experience to be observed, reinforcing negative perceptions in some, and potentially a sense of guilt in others. Treatment and effort need to be the same, even if some employees will continue to be resistant.

\section{REBUILDING TRUST AND REMOVING DISSATISFACTION}

If any awareness of dissatisfaction amongst employees exists, that there has been/is a lack of fairness within the organisation, then a response has to be made. However, it is not enough to simply direct that response to a particular team or level of the organisation, there needs to be an organisational commitment to the removal of dissatisfaction within the organisation.

In order to rebuild trust, the establishment of fairness, action required by all levels needs to be authentic action, continually made over time for the following:

1. Organisational Level - Creation of a specific Culture of Trust and Fairness things start from the top, for any culture to permeate or be given more than pure lip-service; it not only needs to be derived from the leaders and decision-makers in the organisation, but they have to be seen practicing it, not just preaching it. There cannot be one rule for one level and one for others. The culture needs to be authentic and evident.

In terms of removing dissatisfaction, a good starting point is to look at the organisations (1) procedural fairness - the policies and practices in place (and especially their implementation at all levels) - to see whether they provide a transparent and equitable arrangement for employees or whether the system is misinterpreted or applied. Basically, to follow through on what has been promised (terms and conditions, workload, and responsibilities, etc.) and to ensure that it is applied consistently to all employees. At the same time, to consider (2) distributive fairness - to ensure that policies and practices of reward are appropriate for the tasks being undertaken by the employees (such as a qualitative element for our customer service agent discussed earlier as reflection of their work), but not only this, that it is implemented fairly and consistently with the removal of personal bias or influence. Finally, that (3) interactional fairness is consistent - that the implementation and day-to-day implementation of policies and practices by management - from senior management to line-managers and supervisors is consistent with the desired culture of the organisation.

2. Removing dissatisfaction and perceived dissatisfiers through a bridge of an internal vision. If a genuine decision is made to enact change, to build a culture of fairness and transparency, it needs to be communicated effectively, but not just as an exercise in internal public relations, but shown through examples and reinforced through organisational policies and actions to changes in the business environment. 


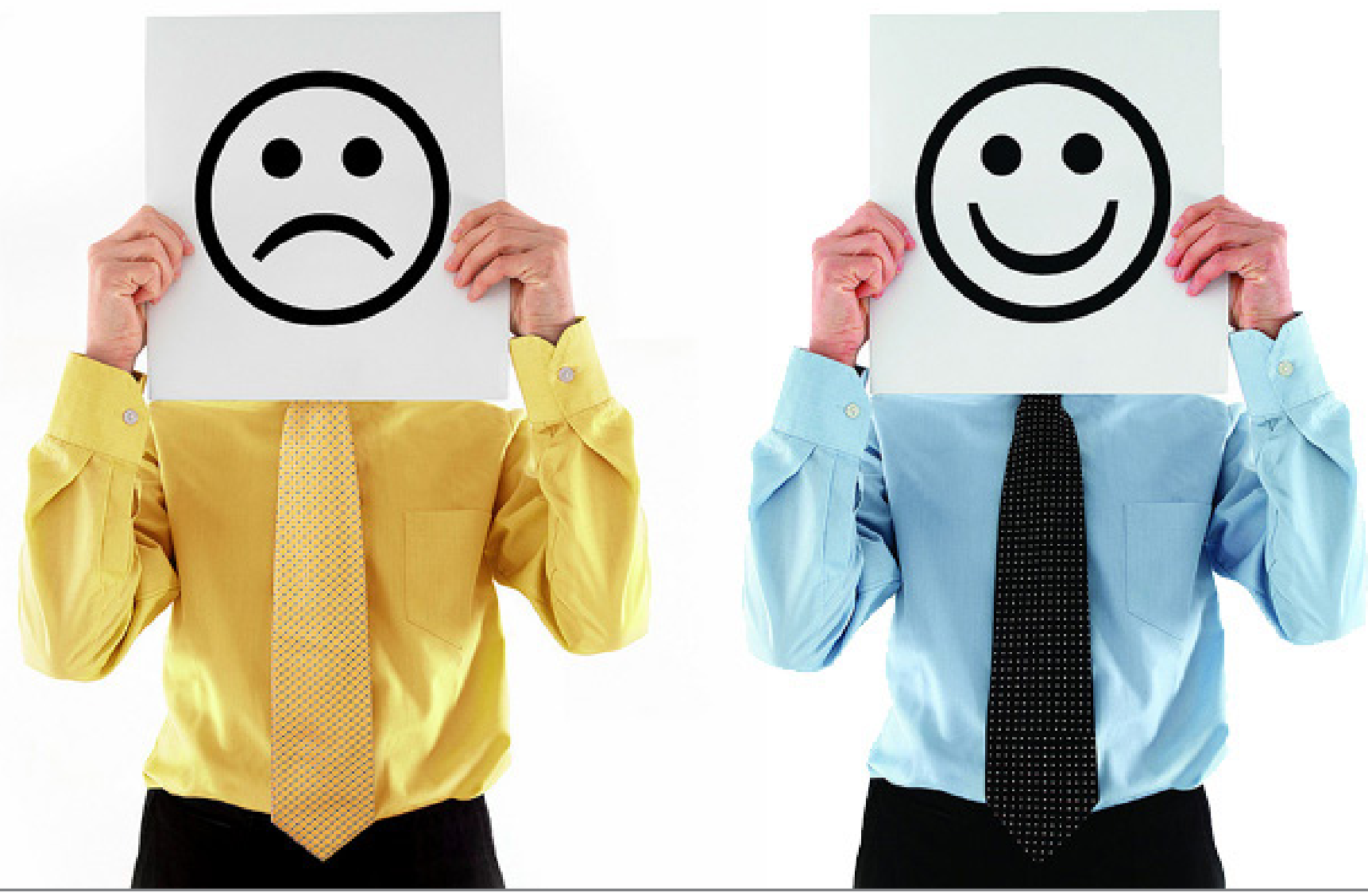

In terms of removing dissatisfaction, it is not enough to simply enact change and assume that everyone will notice or buy-in, but it also has to be shown through the actions of the organisation, especially in terms of confronting challenges. For example, during the 2007/2008 financial crisis, organisations downsized their workforce, reduced salaries of employees, etc. Yet this response, especially the redundancy option, hardly demonstrates the culture of empathy which an organisation might profess. In such a situation, the response has to meet the principles of fairness. In terms of procedural fairness (1), if decisions are made which impact the organisation, they should be in line with stated practices and policies, not something simply done ad hoc and fall evenly on all shoulders, not just those of a few or specific group. (2) Actions taken should be shared by all within the organisation, not simply limited to specific groups and levels. If, for example, a pay-cut has to be introduced, then all members should take one. But of course, it is not enough simply that everyone loses ten percent of their salary; higher earners should have a reduction commensurate with their overall salary compared to those at lower levels on lower amounts. (3) Again, if there is an idea of an internal vision, then it is something which has to be expressed through the levels of management. It is not enough to express it though, it has to be shown through example and practice. With employees noting that dissatisfaction stems from dealings with line management in many cases, the day-to-day approach has to be considered and updated in order to 'live' the vision.

3. Individual Management Levels need to understand, adopt, and follow through on the vision created by the organisation, again so that it is implemented and as they are the ones in direct contact with the employees of the organisation are instrumental in disseminating it.

From a procedural point of view, (1) this approach would have implications with the organisation needing to start from the outset by creating a set of systems, policies and procedures which reflect the approach taken by the organisation. Simply adding to existing systems would most likely not be enough, but require an examination to assess their alignment with the vision which has been created and any identified gaps filled. Beyond this, these policies and procedures need to be communicated and acted on and a system for evaluating their implementation needs to be designed to ensure consistency across the organisation. 
(2) Going beyond a purely procedural approach, a distributive approach is needed to ensure that all elements and levels of the organisation are acting upon and successfully complying with the vision which has been created. Finally, (3) from an interactional point of view, every day contacts between colleagues, employees, and managers (whatever the level) need to be reflecting the ethos on which the organisation has derived. Not only this, the organisation needs to assess the implementation of such ideas through the collection of data, etc. regarding employee health. Open and frank reviews are necessary to ensure it is working appropriately.

The culture which should be created should stress how it cares about the concerns of others, has the ability to listen, understand others' perceptions, and creates a culture of empathy. The culture should also embody consistency - its reactions whether organisational or individual in the face of challenges should be in line with its communicated culture of empathy. Finally, the culture should embody integrity, staying true to its stated values when challenged.

Which can be expressed as the following:

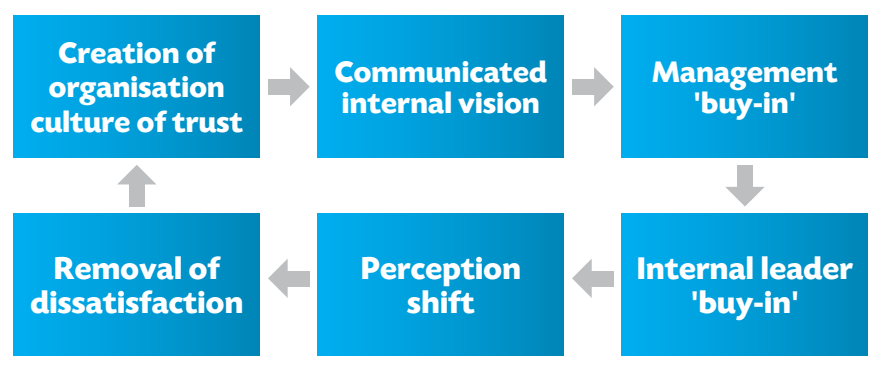

Unfair treatment, the breaking of a psychological contract can lead to dissatisfaction, and 'perceived' dissatisfaction which limit the ability of the organisation to leverage the abilities of its employees to their full extent. Removing dissatisfaction from the working environment allows for the potential for motivation of employees, and only motivated and engaged employees will add significant benefit to the organisation, allowing it to reach its goals. Creating a culture where this can take place stems from the top of the organisation and is required to permeate all levels and practices, and to be seen as authentic, the organisation and its representatives not just 'preaching it', but implementing and actually 'living it' in their daily work and practices. If an organisation can do this, and culture change is not always easy, then the organisation will most likely be in a place to remove those factors that lead to dissatisfaction and inhibit their attempts to motivate and leverage the skills of their employees, and only through authentic practice over time will memory of slights be eased and removed allowing employees to 'buy-in'.

Through this, then perhaps it will be possible for the organisation to create the situation which we started with in the introduction, creation of a workplace which people enjoy going to, looking for challenges, and to achieving more than they thought possible. By providing procedural fairness effectively, we can make our employees feel 'safe', by providing distributive fairness we can make them feel 'protected' and by the proper application of interactional fairness, we can make them want to 'achieve'.

\section{THANKS AND ACKNOWLEDGEMENTS}

This article was originally delivered as a seminar to the business faculty of Prague College in 2015; I would like to thank my colleagues for their feedback and comments during the follow-up session which allowed this idea to be taken further. 


\section{REFERENCES}

Chapman, B. and Sisodia, R. (2015) Everybody Matters: the extraordinary power of caring for your people like family. New York: Penguin Random House.

CIP (2012) Where has all the trust gone? [Online]. Available at: https://www.cipd.co.uk/binaries/where-has-all-thetrust-gone_2012-sop.pdf (Accessed: 1 August 2016).

CIPD (2014) Cultivating Trustworthy Leaders. [Online]. Available at: http://www.cipd.co.uk/binaries/6525\%20 Cultivating\%20trustworthy\%20leaders\%20(web).pdf (Accessed: 26 July 2016).

CIPD (2015a) Employee outlook - Employee views on working life. [Online]. Available at: http://www.cipd.co.uk/binaries/ employee-outlook_2015.pdf (Accessed: 15 June 2016).

CIPD (2015b) Resourcing and Talent Planning. [Online]. Available at: http://www.cipd.co.uk/binaries/resourcingtalent-planning_2015.pdf (Accessed: 18 June 2016).

CIPD (2015c) Getting under the skin of workplace conflict: Tracing the experiences of employees. [Online]. Available at: http://www.cipd. co.uk/binaries/getting-under-skin-workplace-conflict_2015-tracing-experiences-employees.pdf (Accessed: 26 June 2016).

CIPD (2016) Moving the employee well-being agenda forward. [Online]. Available at: http://www.cipd.co.uk/binaries/ moving-employee-well-being-agenda-forward_2016\%20.pdf (Accessed: 29 July 2016).

Deloitte (2016) It's not too late to earn Millennials' loyalty. The Deloitte Millennial Survey 2016 [Online]. Available at: http://www2.deloitte.com/global/en/pages/about-deloitte/articles/gx-millennials-how-to-earn-millennials-loyalty. html\#perfect (Accessed: 24 July 2016).

European Union. Eurofound (2002) Non-permanent employment, quality of work and industrial relations [Online]. Available at: http://www.eurofound.europa.eu/observatories/eurwork/comparative-information/non-permanentemployment-quality-of-work-and-industrial-relations (Accessed: 27 July 2016).

Fernandez-Araoz, C. (2014) '21st Century Talent Spotting', Harvard Business Review, June 2014.

Great Britain. Department for Business Innovation and Skills (2009). Fair Treatment at Work Report: Findings from the 2008 survey [Online]. Available at: https://www.gov.uk/government/uploads/system/uploads/attachment_data/ file/192191/09-P85-fair-treatment-at-work-report-2008-survey-errs-103.pdf (Accessed: 26 July 2016).

Great Britain. Department of Work and Pensions (2013). Employing Older Workers. An employer's guide to today's multi-generational workforce [Online]. Available at: https://www.gov.uk/government/uploads/system/uploads/ attachment_data/file/142751/employing-older-workers.pdf (Accessed: 1 August 2016).

Halogen Software (2015) Employees want a 'family feel' at the heart of the organisations culture [Online]. Available at: http://www.halogensoftware.com/uk/company/news/employees-want-a-family-feel-at-the-heart-of-theirorganisations-culture-finds-latest-employee-outlook-survey (Accessed: 27 July 2016).

Harvard Business Review (2013) The Impact of Employee Engagement on Performance [Online]. Available at: https://hbr. org/resources/pdfs/comm/achievers/hbr_achievers_report_sep13.pdf (Accessed: 27 July 2016).

Herzberg, F. (1968) 'One more time: how do you motivate employees?', Reprint. Harvard Business Review, SeptemberOctober, 1987.

Meister, J. (2012) 'Job Hopping is the 'New Normal' for Millennials: Three Ways to Prevent a Human Resource Nightmare', Forbes, 14 August [Online]. Available at: http://www.forbes.com/sites/jeannemeister/2012/08/14/ job-hopping-is-the-new-normal-for-millennials-three-ways-to-prevent-a-human-resourcenightmare/\#1b6113ae5508 (Accessed: 15 July 2016).

Robinson, S.L. (1996) 'Trust and breach of the psychological contract', Administrative Sciences Quarterly, 41 (4), pp. 574-599.

Schein, E. (1967) 'Introduction', in McGregor, D. The Professional Manager. New York: McGraw-Hill, pp. xi-xiv. 